\title{
AVALIAÇÃO SENSORIAL DE UVAS DE MESA PRODUZIDAS NO VALE DO SÃO FRANCISCO E COMERCIALIZADAS EM JOÃO PESSOA - PB ${ }^{1}$
}

\author{
ROBSON DE JESUS MASCARENHAS ${ }^{2}$, SILVANDA DE MELO SILVA ${ }^{3}$, \\ JULICE DUTRA LOPES ${ }^{2}$, MARIA AUXILIADORA COÊLHO DE LIMA ${ }^{4}$
}

RESUMO - Tomando-se como base o nível crescente de exigência do consumidor por frutas de mesa, as características de qualidade das uvas 'Itália', 'Festival' ('Superior Seedless'), 'Benitaka' e 'Isabel', expostas à venda em três redes de supermercados, na cidade de João Pessoa - Paraíba - Brasil, foram avaliadas em dezembro de 2007. Inicialmente, foram selecionados e treinados julgadores que estabeleceram e definiram os seguintes atributos sensoriais de importância: tonalidade e uniformidade de cor, aroma, firmeza, presença de sementes, suculência, doçura, acidez, sabor e qualidade global. Os diâmetros, comprimentos e pesos das bagas estavam condizentes com os parâmetros comerciais ou varietais. Os conteúdos de sólidos solúveis (SS), com exceção da uva 'Benitaka', apresentaram-se em conformidade com os padrões comerciais. Apenas a cultivar Festival, com a menor acidez titulável (AT), apresentou relação SS/AT aceitável. Foram realizadas três sessões de análises descritivas quantitativas (ADQ), nas quais a uva 'Itália' foi a de melhor sabor e, em conjunto com a apirênica 'Festival', apresentou maiores doçuras e qualidade global. A cultivar Isabel apresentou a cor mais forte, enquanto a Festival foi a melhor no atributo semente. Aplicou-se o Teste de Preferência por Ordenação, no qual as uvas 'Itália' e 'Festival' foram as preferidas.

Termos de Indexação: ADQ, Pós-colheita, qualidade, Vitis.

\section{SENSORIAL EVATUATION OF TABLE GRAPES PRODUCED IN THE SÃO FRANCISCO VALLEY AND TRADED IN JOÃO PESSOA - PB}

\begin{abstract}
Taking into account the increasing demand by table fruits consumers, the quality characteristics of the grapes 'Italy', 'Festival' ('Superior Seedless'), 'Benitaka', and 'Isabel' exposed for sale in three supermarket chains from the city of João Pessoa - Paraíba - Brazil, were evaluated in December, 2007. Initially, it was selected and trained judges that established and defined the following sensorial attributes of importance: tonality and color, uniformity, aroma, firmness, presence of seeds, succulence, sweetness, acidity, flavor, and global quality. Diameters, lengths, and weight of berries were in accordance with the commercial or varietals parameters. The contents of soluble solids (SS), except for the 'Benitaka' grape, were in conformity with the commercial standards. Festival cultivar, the one presenting the lowest titratable acidity (TA), was the only one showing acceptable SS/TA ratio. Three sessions of quantitative descriptive analysis (QDA) were performed, in which 'Italy' grape was the one of better flavor and, together with the seedless 'Festival', presented higher sweetness and global quality. Isabel cultivar presented the best color, while Festival was the best for the attribute seed. The test of preference by ordering was applied, in which 'Italy' and 'Festival' grapes were preferred.
\end{abstract}

Index terms: QDA, Postharvest, quality, Vitis.

\footnotetext{
1(Trabalho 254-09). Recebido em: 30-10-2009. Aceito para publicação em: 13-08-2010.

${ }^{2}$ Aluno do Prog. De Pós-Graduação em Ciência e Tecnologia de Alimentos, CT/UFPB, Campus I João Pessoa - PB, e-mail: robsonjm@ig.com.br, julicedl@gmail.com

${ }^{3}$ Prof. Ph.D. DCFS/CCA/UFPB, Caixa Postal 04, 58.397-000, Areia-PB, email: silvasil@cca.ufpb.br

${ }^{4}$ Pesq. Dr. Embrapa Semi-Árido, Petrolina-PE, e-mail: maclima@cpatsa.embrapa.br
} 


\section{INTRODUÇÃO}

No Brasil, em 2009, foram plantados 82,58 mil hectares de uvas cuja produção somou, aproximadamente, 1,34 milhão de toneladas, das quais aproximadamente $50 \%$ são de uva de mesa (MELLO, 2010). A região do Vale do São Francisco consagrouse como polo produtor e exportador de uvas de mesa de alta qualidade, com elevado padrão tecnológico (GRANGEIRO et al., 2002). Em 2009, neste polo produtor, os Estados de Pernambuco e Bahia plantaram 10,829 mil hectares de videiras, com produção aproximada de 250 mil toneladas de uvas (MELLO, 2010). Novas cultivares têm sido introduzidas em decorrência das novas exigências do mercado pela preferência ao consumo de uvas sem sementes (GRANGEIRO et al., 2002).

O abastecimento de uvas de mesa das redes de supermercados de João Pessoa é suprido em cerca de $80 \%$ pela produção do Vale do São Francisco, sobretudo as cultivares Itália, Festival (Superior Seedless), Benitaka e Isabel (EMPASA, 2010).

No mercado brasileiro de uvas de mesa, percebe-se uma exigência cada vez maior dos consumidores nacionais por frutas de melhor qualidade, não somente quanto ao aspecto, mas também ao sabor, aroma e consistência, além de uma preferência por uvas sem sementes ou apirênicas (LULU et al., 2005).

A determinação da aceitação pelo consumidor é parte crucial no processo de consolidação de um produto no mercado. Neste sentido, a Análise Descritiva Quantitativa (ADQ) é um método de avaliação sensorial que identifica, descreve objetivamente e quantifica os atributos sensoriais de importância (STONE et al., 1974), isto é, ele descreve as propriedades sensoriais e mede a intensidade em que elas foram percebidas pelos provadores com precisão em termos matemáticos (STONE; SIDEL, 1998).

Pesquisas sobre os atributos de qualidade da uva de mesa e sua relação com aceitação e preferências pelo consumidor ainda são escassas no Brasil. No entanto, estudos sobre a preferência do consumidor por cultivares de uvas e seus produtos constitui uma ferramenta importante de regulação de mercado e agregação de valor para o setor produtivo (RIZZON et al., 2000; BARNABÉ et al., 2007).

No contexto deste trabalho, o julgamento sensorial gera informações para a tomada de decisões dos setores produtivos e comerciais para melhor atender às demandas do consumidor.

O objetivo desta pesquisa foi determinar aspectos sensoriais descritivos quantitativos, características físico-químicas e preferências do consumidor referentes às cultivares de uvas produzidas no Vale do São Francisco e comercializadas em redes de supermercados da cidade de João Pessoa - Paraíba - Brasil.

\section{MATERIAL E MÉTODOS}

Nos dias de recebimento nos estabelecimentos comerciais, amostras das uvas (Vitis vinifera L.) 'Itália', 'Benitaka', 'Festival' ('Superior Seedless') e da (Vitis labrusca L) 'Isabel', produzidas no Vale do São Francisco (PE/BA), conforme informações dos comerciantes e descrições contidas nas embalagens, foram adquiridas em dezembro de 2007, de três redes de supermercados de grande porte da cidade de João Pessoa - Paraíba - Brasil. Para cada cultivar, foram coletadas aleatoriamente três caixas com capacidade para $6 \mathrm{~kg}$. Em cerca de 10 horas após a coleta, as uvas foram transportadas em caixas isotérmicas protegidas com plástico bolha à Embrapa - Semiárido em Petrolina - PE, para as análises físico-químicas e confirmação das cultivares e, em 02 horas, ao Laboratório de Biologia e Tecnologia Pós-Colheita da Universidade Federal da Paraíba - Areia - PB, para as avaliações sensoriais.

Para as avaliações físicas, quatro repetições de dois cachos foram utilizadas para a determinação da massa do cacho e das bagas resultantes, em gramas $(\mathrm{g})$, utilizando-se de balança semianalítica; comprimento e diâmetro da baga, em milímetros $(\mathrm{mm})$, foram medidos com paquímetro. As avaliações de acidez titulável - AT, em porcentagem (\%) de ácido tartárico, foram medidas por titulação com $\mathrm{NaOH}$ a 0,1 M, conforme Ranganna (1997), e sólidos solúveis - SS (\%)obtidos por refratômetro digital, de acordo com AOAC (2002), tendo sido utilizadas três repetições de suco obtidos de 50 uvas/repetição. Na avaliação sensorial, realizada com painel treinado, em 27 julgamentos, foi aplicado o teste de Análise Descritiva Quantitativa (ADQ), sendo avaliados a cor, tonalidade, aroma, firmeza, presença de sementes, suculência, doçura, acidez, sabor e a qualidade global, utilizando-se de escalas não estruturadas com 10 centímetros de comprimento. O teste de ADQ foi realizado conforme Faria e Yotsuyanagi (2002), cujo desenvolvimento implicou as seguintes etapas: $1^{\text {a }}$ ) Recrutamento entre alunos e professores do Programa de PósGraduação de Tecnologia de Alimentos e Agronomia da Universidade Federal da Paraíba, Câmpus de João Pessoa e Areia; $2^{\mathrm{a}}$ ) Seleção, através do teste de discriminação dos sabores básicos; $3^{\mathrm{a}}$ ) Treinamento realizado em três sessões, para maior entendimento e familiaridade com a metodologia, utilizando três diferentes amostras de uvas; $4^{\mathrm{a}}$ ) Desenvolvimento 
da terminologia descritiva, inicialmente de forma individual e posteriormente sob a orientação de um moderador, identificação consensual dos atributos mais relevantes, descrevendo os respectivos significados e estabelecendo a ordem de percepção. Em seguida, foi elaborada uma lista com a definição dos termos descritivos das amostras (Tabela 1) e propostas referências para exemplificar cada termo descritor (STONE; SIDEL, 1998); $5^{\text {a }}$ ) Avaliação do desempenho da equipe, considerando aqueles que obtiveram $80 \%$ de acerto nos testes dos sabores básicos e $100 \%$ de presença nas três sessões de treinamento; $6^{\mathrm{a}}$ ) Testes definitivos em triplicata. Em complementação à $\mathrm{ADQ}$, desenvolveu-se, ainda, o teste Afetivo de Preferência por Ordenação de acordo com a ABNT (1994).

Análise Estatística - A Análise Descritiva Quantitativa foi efetuada em triplicata, mediante emprego de delineamento em blocos completos casualizados, considerando como tratamentos as quatro cultivares de uvas, como blocos os julgadores treinados e como repetição as três sessões intercaladas. Os cálculos foram realizados através do programa SPSS for Windows Evaluation Edition 14.0 (SPSS. INC., 2005), considerando o nível de 5\% de probabilidade $(p \leq 5 \%)$. Para maior consistência dos resultados paramétricos, aplicaram-se os testes de Homogeneidade Amostral e o de Distribuição Normal - Kolmogorov - Smirnov (K-S). Com dados submetidos à Análise de Variância (ANOVA - teste $F$ ), para os sem Homogeneidade entre amostras, utilizouse o teste de Robustez de Welch e, em seguida, o teste de Tukey, conforme Stone e Sidel (1998).

No teste de Preferência por Ordenação, os dados foram analisados pela Diferença Mínima Significativa (DMS) da Soma de Ordens para comparação, considerando $\mathrm{p}<5 \%$, com base no Teste não paramétrico de Friedman e Tabela de Newelle e Mcfarlane, conforme Chaves (2001).

\section{RESULTADOS E DISCUSSÃO}

As uvas 'Itália' e 'Benitaka' foram estatisticamente superiores nas avaliações físicas (Tabela 2). A uva 'Isabel' apresentou os menores valores, enquanto a uva apirênica 'Festival' obteve valor médio intermediário em relação às demais.

Choudhury (2001) considera comerciais as bagas de uvas com diâmetros de $18 \mathrm{~mm}$ a 26 $\mathrm{mm}$; neste aspecto, as uvas 'Itália', 'Festival' e 'Benitaka' apresentaram-se dentro destes padrões. A uva 'Isabel', com diâmetro médio $(17,6 \mathrm{~mm})$, foi ligeiramente inferior ao mínimo, porém acima dos padrões varietais de $16,7 \mathrm{~mm}$ de diâmetro, 15,7 mm de comprimento e peso de 3,0 g, valores estes recomendados por Rizzon et al. (2000).

Choudhury (2001) e Albuquerque (1996) citam que uvas de mesa com os teores de sólidos solúveis (SS) iguais ou superiores a $15 \%$ são consideradas aptas para a comercialização, na região Nordeste do Brasil. Neste contexto, verifica-se que as cultivares Isabel, Itália e Festival foram superiores e apresentaram-se dentro dos padrões estabelecidos, exceto a 'Benitaka' com valor médio inferior ao mínimo recomendado (Tabela 3).

Em relação à acidez titulável (AT), valores acima de 1,5 são considerados altos, conforme Carvalho e Chitarra (1984). Neste estudo, as cultivares apresentaram-se em conformidade com este valor referencial. A apirênica 'Festival' obteve o menor teor de acidez titulável, influenciando positivamente nas avaliações sensoriais referentes à acidez, preferência e qualidade global, o que também foi relatado por Grangeiro et al. (2002) e Camargo (1998).

Na relação SS/AT (Tabela 3), Albuquerque (1996) e Choudhury (2001) consideram desejável o quociente igual ou maior que 20. Sob este aspecto, a cultivar apirênica Festival apresentou notória superioridade em relação às demais, principalmente, devido à baixa acidez titulável.

Na Análise Descritiva Quantitativa, constatou-se, com exceção da suculência, que os demais atributos sensoriais apresentaram diferenças estatísticas, conforme apresentado na Tabela 4.

$\mathrm{Na}$ aparência, Choudhury (2001) considera a cor o atributo mais preferido. Neste aspecto, os resultados deste trabalho demonstram a superioridade da uva 'Isabel' (tinta muito escura), seguida da 'Benitaka' (tinta) e 'Itália' (verde de tom amarelo), com notas medianas, e a 'Festival' (verde) apresentando-se inferior (Tabela 4).

Para o atributo tonalidade da cor, a cultivar tinta 'Isabel', também denominada de uva preta por comerciantes (PIVA et al., 2006b), apresentou-se significativamente superior, enquanto a 'Benitaka' de nuança rosada obteve o segundo lugar, seguida conjuntamente pelas cultivares Itália e Festival, ambas de tons claros e comumente denominadas uvas brancas (Tabela 4).

Em relação à firmeza, a cultivar Festival expressou a maior resistência, com notas próximas ao extremo máximo da escala, podendo ser designada de uva muito firme, seguida pela 'Benitaka', enquanto a 'Isabel', com nota abaixo do ponto mediano, apresentou a menor firmeza (Tabela 4), concordando, assim, com a denominação de uva macia, citada por Rizzon et al. (2000). 
As cultivares Benitaka e Itália, igualmente citadas por Mascarenhas et al. (2006) e em conjunto com a Festival, possuem aromas irrelevantes. A cultivar 'Isabel' apresentou aroma forte (Tabela 4), assim denominado, também, por Rizzon et al. (2000), ao citarem que: o aroma da uva 'Isabel' é percebido facilmente por ocasião da maturação, caracterizando-se principalmente pelo aroma floral agradável de antranilato de metila.

No aspecto presença ou ausência de sementes, a cultivar apirênica Festival foi a mais agradável, com notas próximas ao extremo máximo, enquanto as demais obtiveram médias próximas ao extremo desagradável (Tabela 4). Este resultado concorda com Piva et al. (2006a), ao citarem que a uva 'Festival' foi muito valorizada nos testes sensoriais pela ausência de sementes. Entretanto, embora a ausência de sementes seja um aspecto desejável, este não é decisivo quanto à aceitação ou rejeição de uma cultivar de uva de mesa (CLIFF et al., 1996).

$\mathrm{Na}$ percepção do atributo suculência, as quatro cultivares em estudo, sem diferenças significativas, apresentaram-se agradáveis, com notas médias um pouco acima do ponto central da escala. No atributo doçura, observaram-se dois grupos distintos: o primeiro com maior nota média, composto pela 'Itália' e 'Festival'; e o segundo, menos doce, formado pela 'Benitaka' e 'Isabel'. Em relação à acidez, a cultivar Festival expressou sensação ácida muito baixa, seguida estatisticamente da 'Itália', posteriormente da 'Benitaka' e, por último, da 'Isabel', com forte sabor ácido (Tabela 4). Estes resultados concordam com os ensaios físicoquímicos aqui realizados e, também, relatados por Grangeiro et al. (2002).

No atributo sabor, a uva 'Itália', com notas próximas ao extremo "mais saboroso" da escala, foi estaticamente superior às demais cultivares que não diferiram entre si e apresentaram médias muito próximas ao centro da escala sensorial (Tabela 4). Piva et al. (2006a) avaliaram e descreveram sensorialmente as uvas 'Flame Seedless', 'Superior Seedless' ou 'Festival', 'Cardinal', 'Victoria' e 'Red-Globe' na Espanha, detectando que o sabor, seguido pela suculência, foi o elemento determinante na aceitação das duas primeiras cultivares. Também na Espanha, a cultivar Itália foi a preferida predominantemente pela sua suculência (PIVA et al., 2008).

A qualidade global conglomera os demais atributos que perfazem o perfil sensorial (Figura 1). Neste aspecto, assim como a doçura, formaramse dois grupos distintos, sendo que, no primeiro, tem-se a 'Itália' e a apirênica 'Festival', que foram superiores às demais, enquanto a 'Benitaka' e a 'Isabel' compuseram o segundo grupo de qualidade global mediana, com notas sensoriais muito próximas ao centro da escala.

Mascarenhas et al. (2006) reportaram que as uvas 'Itália' e 'Benitaka' foram as mais preferidas em seus experimentos, as quais estavam dentro dos padrões comerciais, e o sabor doce e a tonalidade de cor, nesta ordem, foram os atributos determinantes da qualidade global. Para o mercado espanhol, na definição dos atributos de qualidade ideais para uva de mesa, o bom sabor/doçura foi apontado como o mais importante por $26,7 \%$ dos consumidores (PIVA et al., 2006b). Cliff et al. (1996), em estudo realizado com doze cultivares de uvas de mesa, reportaram que o sabor, elevada doçura e a crocância foram correlacionados positivamente com a preferência do consumidor. Neste experimento, os atributos de qualidade, determinantes para a aceitação e preferência pelos consumidores para as uvas avaliadas, foram o sabor e a doçura. Assim, pode-se inferir que a baixa preferência pela uva 'Benitaka' está correlacionada com o baixo teor de sólidos solúveis igual a 13,63\%, ratificando a necessidade de atender ao padrão comercial mínimo de $15,0 \%$.

No teste de Preferência por Ordenação (Figura 2), as cultivares Itália e a Festival foram as mais preferidas em relação à Benitaka e Isabel. No mercado espanhol, a uva 'Festival' ou 'Superior Seedlees' (PIVA et al., 2006a) e 'Itália' (PIVA et al., 2008) foram as preferidas quando comparadas a outras cultivares normalmente comercializadas. Neste trabalho, a uva 'Itália', de melhor sabor e doçura, em conjunto com a uva apirênica 'Festival', de melhor doçura, menor acidez, melhor relação SS/AT e mais agradável no aspecto sementes, foram as melhores nos testes sensoriais Descritivos Quantitativos e as mais preferidas no teste de Ordenação. Estes resultados evidenciam forte consistência, uma vez que, independentemente dos testes estatísticos utilizados, concordam integralmente com os obtidos na qualidade global. 
TABELA 1- Glossário utilizado na avaliação sensorial de cultivares de uvas de mesa.

\section{Descritores}

1. Tonalidade de Cor Principal (fraca - forte)

2. Uniformidade de Cor Principal Relativa à parte externa da baga, refere-se à intensidade de variação (baixa - alta)

3. Aroma Característico (fraco - forte)

4. Firmeza

(menos - mais)

5. Sementes (desagradável - agradável)

6. Suculência (pouco-mais)

\section{Doçura}

(menos - mais)

\section{Acidez}

(menos - mais)

\section{Sabor}

(menos saboroso - mais saboroso)

10. Qualidade Global

(ruim - excelente)
Definições

Relativa à principal cor externa da baga, refere-se à dimensão da sensação visual da cor que incide nos receptores visuais.
Propriedade organoléptica peculiar da uva e perceptível pelo órgão olfativo durante a degustação.

Relacionada à força necessária para provocar uma determinada deformação, através da compressão manual e bucal.

Sensação de resistência da semente à mordida.

Quantidade de suco liberado quando a fruta é pressionada contra o palato.

Gosto primário produzido por soluções aquosas de várias substâncias, tipo açúcar sacarose.

Gosto primário produzido por soluções aquosas de várias substâncias, tipo ácido cítrico e tartárico.

Referiu-se especificamente à experiência mista, mas unitária, da sensação gustativa e trigemial percebida durante a degustação e denominada de sabor.

Soma dos fatores de qualidade que contribuem na determinação da aceitação do produto.

TABELA 2 - Características físicas de uvas de mesa produzidas no Vale do São Francisco (PE/BA) e comercializadas na cidade de João Pessoa - Paraíba, 2007.

\begin{tabular}{ccccc}
\hline \multirow{2}{*}{ Avaliações } & \multicolumn{4}{c}{ Valores Médios por Cultivares de Uvas } \\
\cline { 2 - 5 } & Benitaka & Festival & Isabel & Itália \\
\hline Peso/Baga (g) & $9,3 \mathbf{a}$ & $7,2 \mathbf{b}$ & $3,7 \mathbf{c}$ & $9,4 \mathbf{a}$ \\
Diâmetro/Baga (mm) & $23,5 \mathbf{a}$ & $21,4 \mathbf{b}$ & $17,6 \mathbf{c}$ & $23,7 \mathbf{a}$ \\
Comprimento/Baga (mm) & $28,3 \mathbf{a}$ & $26,3 \mathbf{b}$ & $20,1 \mathbf{c}$ & $28,3 \mathbf{a}$ \\
\hline
\end{tabular}

(*)Médias com letras diferentes na mesma linha indicam diferença significativa $(\mathrm{p}<0,05)$ entre cultivares, pelo Teste de Tukey.

TABELA 3 -Médias de análises químicas das uvas produzidas no Vale do São Francisco (PE/BA) e comercializadas em João Pessoa - Paraíba, 2007.

\begin{tabular}{crrrr}
\hline \multirow{2}{*}{ Avaliações } & \multicolumn{4}{c}{ Valores Médios por Cultivares de Uvas } \\
\cline { 2 - 5 } & Benitaka & Festival & \multicolumn{1}{c}{ Isabel } & \multicolumn{1}{c}{ Itália } \\
\hline SS (\%) & $13,63 \mathbf{~ b}$ & $15,13 \mathbf{~ a}$ & $15,97 \mathbf{a}$ & $15,30 \mathbf{a}$ \\
AT (\% Ácido Tartárico) & $0,74 \mathbf{a}$ & $0,43 \mathbf{~ b}$ & $0,94 \mathbf{~ a}$ & $0,78 \mathbf{~ a}$ \\
SS/AT & $18,50 \mathbf{b}$ & $34,93 \mathbf{~ a}$ & $17,12 \mathbf{~ b}$ & $19,87 \mathbf{~ b}$ \\
\hline
\end{tabular}

(*)Médias com letras diferentes na mesma linha indicam diferença significativa $(\mathrm{p}<0,05)$ entre cultivares, através do teste de Tukey 
TABELA 4 - Análise Descritiva Quantitativa - notas médias sensoriais para cultivares de uvas produzidas no Vale do São Francisco (PE/BA) e comercializadas em João Pessoa-Paraíba, 2007.

\begin{tabular}{|c|c|c|c|c|c|c|c|c|}
\hline \multirow{3}{*}{$\begin{array}{c}\text { Atributos Sensoriais } \\
\text { Cor }\end{array}$} & \multicolumn{8}{|c|}{ Cultivares de Uvas, Médias e Desvios-Padrão $( \pm)$ de Notas Sensoriais } \\
\hline & \multicolumn{2}{|c|}{ Benitaka } & \multicolumn{2}{|c|}{ Festival } & \multicolumn{2}{|c|}{ Isabel } & \multicolumn{2}{|c|}{ Itália } \\
\hline & $7,3 \mathbf{b a}$ & $\pm 1,8$ & $6,3 \mathbf{c}$ & $\pm 2,0$ & $7,4 \mathrm{a}$ & $\pm 1,7$ & $6,4 \mathbf{c b}$ & $\pm 1,4$ \\
\hline Tonalidade & $6,9 \mathbf{b}$ & $\pm 1,6$ & $5,4 \mathbf{c}$ & $\pm 2,0$ & $8,3 \mathbf{a}$ & $\pm 1,4$ & $5,5 \mathbf{c}$ & $\pm 2,0$ \\
\hline Aroma & $3,2 \mathbf{b}$ & $\pm 2,0$ & $3,2 \mathbf{b}$ & $\pm 1,5$ & $6,4 \mathbf{a}$ & $\pm 2,5$ & $3,4 \mathbf{b}$ & $\pm 1,9$ \\
\hline Firmeza & $5,9 \mathbf{b}$ & $\pm 2,1$ & $7,1 \mathbf{a}$ & $\pm 2,3$ & $4,5 \mathbf{c}$ & $\pm 1,8$ & $6,3 \mathbf{b a}$ & $\pm 1,7$ \\
\hline Sementes & $4,9 \mathbf{b}$ & $\pm 1,9$ & $8,5 \mathbf{a}$ & $\pm 1,0$ & $4,2 \mathbf{b}$ & $\pm 1,4$ & $4,3 \mathbf{b}$ & $\pm 1,6$ \\
\hline Suculência & $6,5 \mathbf{a}$ & $\pm 1,9$ & $5,6 \mathbf{a}$ & $\pm 2,5$ & $6,2 \mathbf{a}$ & $\pm 1,8$ & $6,6 \mathbf{a}$ & $\pm 1,3$ \\
\hline Doçura & $5,2 \mathbf{b}$ & $\pm 2,1$ & $6,4 \mathbf{a}$ & $\pm 2,1$ & $4,6 \mathbf{b}$ & $\pm 1,9$ & $6,4 \mathbf{a}$ & $\pm 2,2$ \\
\hline Acidez* & $5,7 \mathbf{b}$ & $\pm 2,0$ & $2,9 \mathbf{d}$ & $\pm 1,8$ & $6,9 \mathbf{a}$ & $\pm 1,6$ & $4,5 \mathbf{c}$ & $\pm 2,1$ \\
\hline Sabor & $6,0 \mathbf{b}$ & $\pm 1,6$ & $6,0 \mathbf{b}$ & $\pm 2,0$ & $5,2 \mathbf{b}$ & $\pm 1,6$ & $7,1 \mathbf{a}$ & $\pm 1,5$ \\
\hline Qualidade Global & $5,6 \mathbf{b}$ & $\pm 1,9$ & $6,7 \mathbf{a}$ & $\pm 2,0$ & $5,1 \mathbf{b}$ & $\pm 1,6$ & $7,2 \mathbf{a}$ & $\pm 1,3$ \\
\hline
\end{tabular}

(*)Médias com letras diferentes na mesma linha indicam diferença significativa $(\mathrm{p}<0,05)$, pelo Teste de Duncan.

- - - Benitaka $\multimap-$ Festival $\triangle$ Isabel $\triangle$ Itália

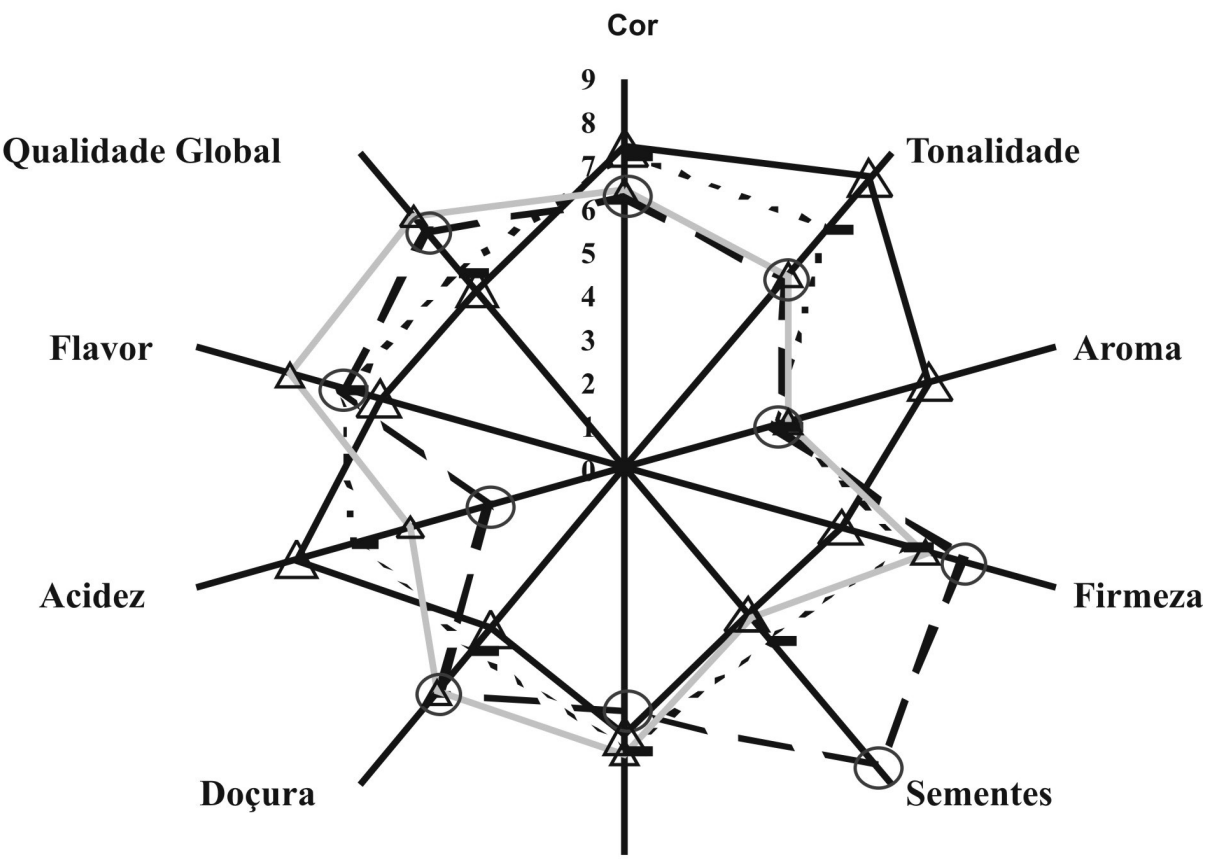

Suculência

FIGURA 1 - Perfil Sensorial da qualidade de cultivares de uvas de mesa produzidas no Vale do São Francisco (PE/BA) e comercializadas em João Pessoa - Paraíba, 2007. 


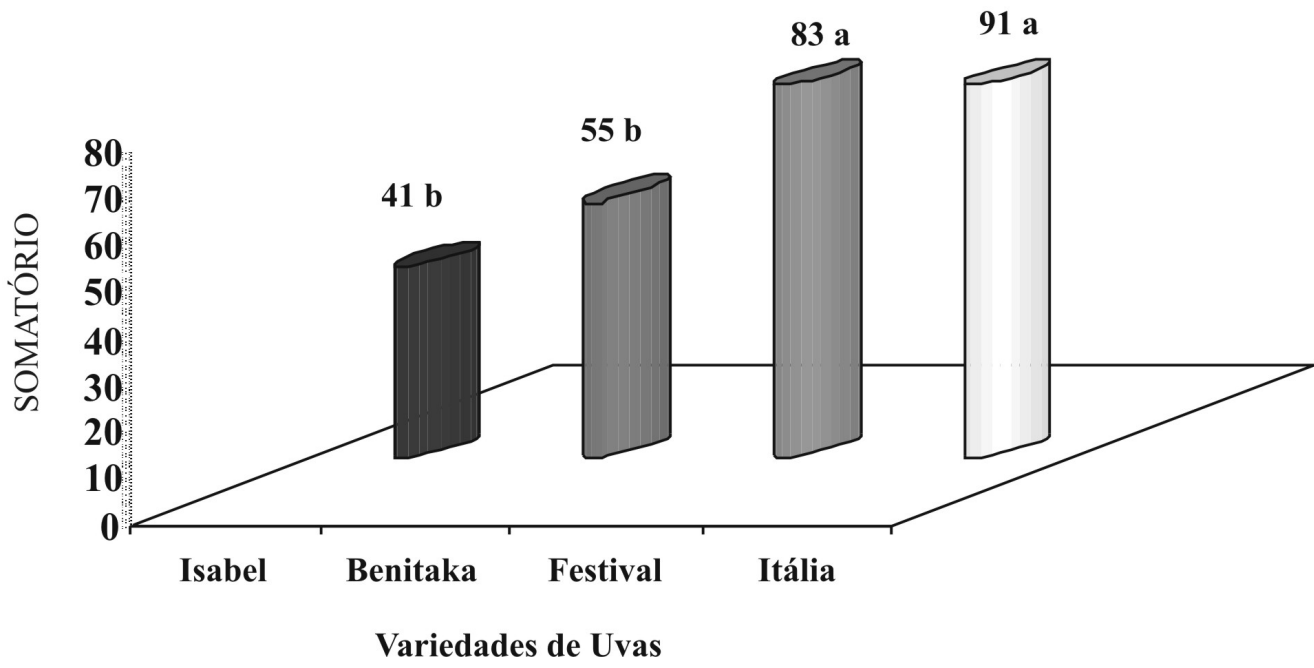

FIGURA 2 - Somatório de notas (teste de Preferência por Ordenação) para uvas produzidas no Vale do São Francisco (PE/BA) e comercializadas em João Pessoa - Paraíba, 2007. DMS = 25.

\section{CONCLUSÕES}

Com base nas condições que as avaliações foram realizadas, pode-se concluir que:

1-As uvas 'Itália' e 'Festival' comercializadas em João Pessoa apresentam as melhores características para as variáveis avaliadas. A cultivar Benitaka está sendo comercializada com pouca doçura sensorial e baixo teor de SS - padrão comercial mínimo de $15,0 \%$.

2-As uvas 'Itália', 'Benitaka' e 'Isabel' estão sendo ofertadas com relação SS/AT abaixo do padrão mínimo comercial, igual a 20,0.

3-Os parâmetros físicos das uvas 'Itália', 'Benitaka' e 'Festival' encontram-se em conformidade com os padrões varietais e comerciais, e a uva 'Isabel', com os padrões varietais.

4-O sabor, doçura, boa relação SS/AT e ausência de sementes caracterizam os atributos de maior destaque das cultivares vencedoras em relação à qualidade global e ordem de preferência.

\section{REFERÊNCIAS}

ABNT- Associação Brasileira De Normas Técnicas. Teste de ordenação em análise sensorial. São Paulo: ABNT NBR 13170, 1994. 7 p.

ALBUQUERQUE, T.C.S. de. Uvas para exportação aspectos técnicos da produção. Brasília: Embrapa - SPI, 1996. 53p. (Série Publicações Técnicas FRUPEX, 25).

AOAC. Association of Official Analytical Chemists. Official methods of analysis of AOAC international. 17. ed., Washington, 2002.

BARNABÉ, D.; VENTURINI FILHO, W.G.; BOLINI, H.M.A. Análise Descritiva Quantitativa de Vinhos Produzidos com Uvas Niágara Rosada e Bordô. Brazilian Journal of Food Technology, Campinas,v. 10, n. 2, p. 122-129, 2007.

CAMARGO, U. A. Cultivares para a viticultura tropical no Brasil. Informe Agropecuário, Belo Horizonte, v. 19, n. 194, p. 14-19, 1998.

CARVALHO, V.D.; D.; CHITARRA, M.I.F. Aspectos qualitativos da uva. Informe Agropecuário, Belo Horizonte, v.10, n.117, p.75-79, 1984. 
CHAVES, J. B. P. Métodos de diferença em avaliação sensorial de alimentos e bebidas. Viçosa: UFV, 2001. 91 p. (Cadernos Didáticos, 33).

CHOUDHURY, M. M. (Ed.). Uva de mesa: póscolheita. Brasília: Embrapa Informação Tecnológica; Petrolina-PE: Embrapa Semi-Árido, 2001. 55 p. (Frutas do Brasil, 12).

CLIFF, M.A.; DEVER, M.C.; REYNOLDS, A. G. Descriptive profiling of new and commercial British Columbia table grape cultivars. American Journal of Enology and Viticulture, Stanford, v.47, n.3, p. 301-308, 1996.

EMPASA - Empresa Paraibana de Abastecimento e Serviços Agrícolas. Oferta e cotação de preços. Disponível em: <http://www.empasa.pb.gov.br/ > . Acesso em: 04 abr. 2010.

FARIA, E. V. de; YOTSUYANAGI, K. Técnicas de análise sensorial. Campinas: LAFISE/ITAL, 2002. $116 \mathrm{p}$.

GRANGEIRO, L.C.; LEÃO, P.C.S.; SOARES, J.M. Caracterização fenológica e produtiva da variedade de uva Superior Seedless cultivada no Vale do São Francisco. Revista Brasileira de Fruticultura, Jaboticabal, v. 24, n. 2, p. 552-554, 2002.

LULU, J.; CASTRO, J.V.; PEDRO JÚNIOR, M. J. Efeito do microclima na qualidade da uva de mesa 'Romana' (A1105) cultivada sob cobertura plástica. Revista Brasileira de Fruticultura, Jaboticabal, v. 27, n. 3, p. 422-425, 2005.

MASCARENHAS, R.J.; GUERRA, N.B.; LEAO, P.C.S.; SILVA, C.G.M. Características Sensoriais de uvas finas de mesa cultivadas no Vale do Submédio São Francisco. In: CONGRESSO BRASILEIRO DE CIÊNCIA E TECNOLOGIA DE ALIMENTOS, 20., 2006, Curitiba. Anais... v.1, p. 1-1.
MELLO, L. M. R. Área e produção de uvas: panorama mundial. Bento Gonçalves: Embrapa Uva e Vinho. 6p. 2010. Disponível em: <www.embrapa. cnpuv.br>. Acesso em: mar. 2010.

PIVA, C.R.; LOPEZ G.J.L.; MORGAN, W. Evaluación del nivel de aceptabilidad para las variedades Italia, Napoleón y Redglobe en el mercado español. Revista Brasileira de Fruticultura, Jaboticabal, v. 30, n. 2, p.361-364, 2008.

PIVA, C.R.; LOPEZ G.J.L.; MORGAN, W. Nivel de aceptabilidad para cinco variedades de uva de mesa em el mercado español. Revista Brasileira de Fruticultura, Jaboticabal, v.28, n. 1, p. 60-63, 2006a.

PIVA, C.R.; LOPEZ G.J.L.; MORGAN, W. The ideal table grapes for the Spanish market. Revista Brasileira de Fruticultura, Jaboticabal, v. 28, n. 2, p. $258-261,2006 \mathrm{~b}$.

RANGANNA, S. Handbook of analysis and quality control for fruit and vegetable products. 4. ed. New Delhi: McGraw-Hill, 1997.

RIZZON, L.A; MIELE, A; MENEGUZZO, J. Avaliação da uva cv. Isabel para a elaboração de vinho tinto. Ciência e Tecnologia de Alimentos, Campinas, v.20, n. 1, p. 115-121, 2000.

SPSS. 14.0 for windows evaluation version: $c$ omputer program. Chicago, 2005.

STONE, H.; SIDEL, J.L. Quantitative descriptive analysis: developments, application, and the future. Food Technology, Chicago, v. 52, p. 48-52, 1998.

STONE, H.; SIDEL, J.L.; OLIVER, S.; WOOSLEY, A.; SINGLETON, R.C. Sensory evaluation by Quantitative Descriptive Analysis. Food Technology, Chicago, v. 28, n. 11, p. 24-34, 1974. 